\title{
RESPIRATORY GRANULOMATOSIS WITH POLYARTERITIS NODOSA (WEGENER'S SYNDROME)
}

\author{
BY \\ N. S. Plummer, J. H. ANGEL, D. B. SHAW, and K. F. W. HINSON \\ From the London Chest Hospital and Farnborough Hospital, Kent
}

(RECEIVED FOR PUBLICATION JUNE 15,1956 )

In 1931 Klinger published a case of nasal sinusitis which terminated in renal failure. There have since been a number of reports of a syndrome characterized clinically by a combination of intractable rhinitis or pulmonary symptoms, manifestations of polyarteritis nodosa, and renal failure. Pathologically, the disease is recognized by the association of necrotizing granulomata of the respiratory tract and generalized arteritis with focal glomerulitis. The syndrome has been known as Wegener's granulomatosis since his detailed description of three cases in 1936 and 1939.

In 1954 Fahey, Leonard, Churg, and Godman collected 22 cases from the literature and added seven of their own. The pathological features of these 29 cases were analysed by Godman and Churg (1954). Since this review six more have been reported by McCallum (1954), Seidelin and Willcox (1954), Milner (1955), and Walton and Leggat (1956).

We present two further cases of this syndrome. Each presented a difficult problem in the diagnosis of a respiratory illness.

\section{CASE REPORTS}

CASE 1.-A childless, married woman of 40 years was admitted to the London Chest Hospital on November 9, 1955, with a provisional diagnosis of pneumonia complicating sinus infection. She died 13 days later in oliguric uraemia.

A rash resulted from penicillin injections given for gastroenteritis in 1945, but there was no other history of allergy in herself or her family and she had not had sulphonamides before. Her health had been good, with no previous urinary symptoms, and she denied taking an abortifacient.

The illness lasted 10 weeks. It started early in September with swollen, watery eyes, a blocked nose, and incessant sneezing. All sense of taste and smell was lost and then there was swelling and pain below each eye in turn. This went on for six weeks and a low-grade fever developed. Between October 17 and $24,16 \mathrm{~g}$. of sulphadimidine was given. Because of nausea and vomiting, aureomycin was substituted for this on October 24, but vomiting continued to the end.

On October 27 she complained of burning pains in the legs and of some difficulty in walking. A slight cough developed; radiographs showed soft infiltration in the left mid zone and a few small areas of mottling elsewhere (Fig. 1). Films of the sinuses showed a fluid level in the right antrum. From November 5 the urine was coffee-coloured and reduced in volume.

On November 9 she was drowsy, with a pale, puffy face and bilateral conjunctivitis, and complained of pain down the back of the left leg. There were no abnormal physical signs apart from dry crusting in the nose and some rales in the left axilla. The fundi

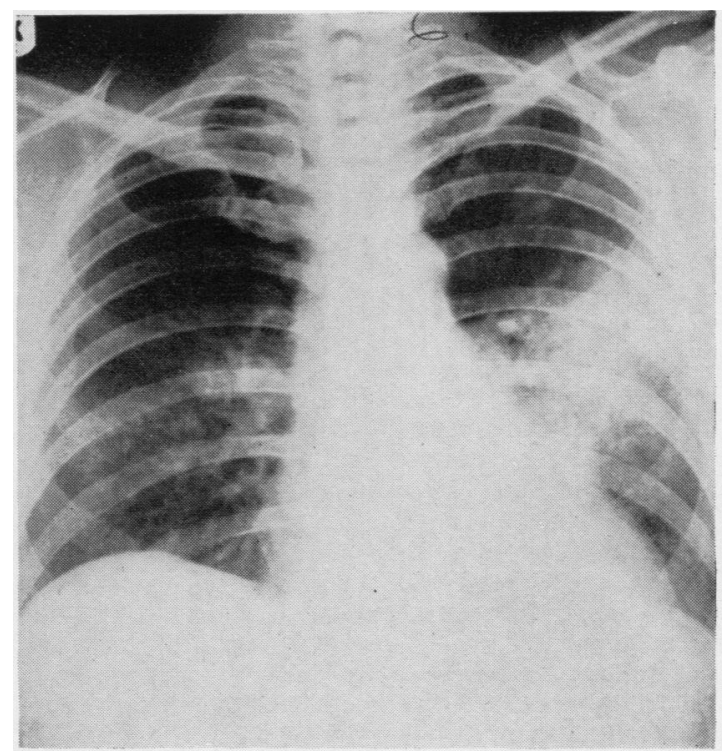

Fig. 1.-Case 1: radiograph of the chest on November 1, 1955 , showing soft infiltration in the left mid zone and scattered mottling elsewhere. 


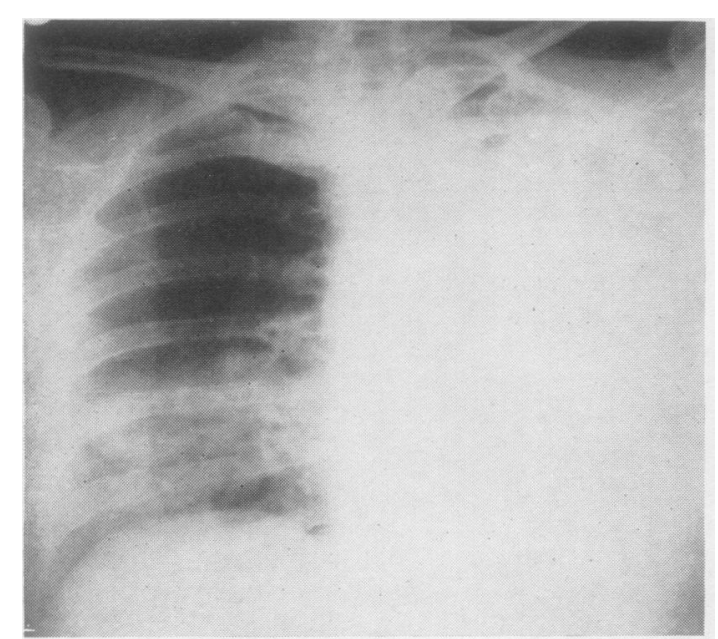

FIG. 2.-Case 1: radiograph of the chest on November 21, 1955, showing almost complete opacity of the left side and extension of infiltration on the right side.

were normal and the blood pressure was $145 / 80$ $\mathrm{mm}$. Hg. She passed no urine, and on the second day $11 \mathrm{oz}$. $(300 \mathrm{ml}$.) of bloody urine were drawn off by catheter. This contained many red cells and was sterile on culture. From the sputum only coliform bacilli and monilia were grown. The blood urea level was $320 \mathrm{mg}$. per $100 \mathrm{ml}$., the sedimentation rate 135 $\mathrm{mm}$. in the first hour (Westergren), and haemoglobin $56 \%$. Plasma electrolytes were: sodium $250 \mathrm{mg}$., chloride $503 \mathrm{mg}$., potassium $22 \mathrm{mg}$., alkali reserve 20 vol. per $100 \mathrm{ml}$.

Treatment with penicillin, one million units twice a day, was begun after test doses had produced no reaction, but was abandoned on the third day when urticaria developed. From November $11 \quad 50 \%$ dextrose was run into the inferior vena cava and nothing was given by mouth. For the last four days A.C.T.H. gel, 40 units b.d., was given intramuscularly. The blood electrolytes were corrected except for the serum potassium level, which continued to rise. The E.C.G. showed large spiky $T$ waves. Transfusion of 3 pints of packed cells did not control increasing anaemia.

There was no fever while the patient was in hospital and the blood pressure and fundal appearances remained normal. The urinary output fell to $2 \mathrm{oz}$. $(56 \mathrm{ml}$.) a day, but rose to an average of $8 \mathrm{oz}$. (224 $\mathrm{ml}$.) in the last five days. The blood urea rose to $520 \mathrm{mg}$. and fell to $400 \mathrm{mg}$. per $100 \mathrm{ml}$. towards the end. The nasal mucosa remained swollen with widespread crusting, but the patient's sense of smell and taste returned. The skin showed urticaria, erythema, and finally a striking haemorrhagic herpetiform eruption over the hands and wrists.

Despite vigorous treatment the uraemia pursued its inexorable course with pericarditis and bleeding from the kidneys, lungs, vagina, and into the skin lesions. Signs of consolidation developed in the left lung.
Radiologically, the mottling in the right lung increased and the left lung became almost completely opaque (Fig. 2). On November 22 she became intensely dyspnoeic and died.

The blood was Group $A$ and Rhesus positive. Leucocytes numbered 17,600 per c.mm., of which neutrophils were $88 \%$, eosinophils $2 \%$, lymphocytes $6 \%$, and mononuclears $4 \%$. Two tests for L.E. cells were negative. Serum proteins totalled $6 \mathrm{~g}$. per 100 $\mathrm{ml}$, of which $3.1 \mathrm{~g}$. was albumin and $2.9 \mathrm{~g}$. globulin. The serum calcium level was $9 \mathrm{mg}$.\%. Leptospiral agglutination tests were negative. The Wassermann and Kahn tests were negative. The urine was always blood-stained, and some cellular, waxy, and hyaline casts were seen.

Post-mortem Examination.-There was haemorrhagic crusting about the nares and in the nasal cavity. The trachea and bronchi contained heavily bloodstained mucus. Slight superficial ulceration was present at the carina.

Both lungs were oedematous. There were both scattered and confluent areas of recent haemorrhags in all lobes of both lungs, but the changes were more extensive on the left side. Also, particularly on the left side, there were areas of cream-coloured necrosis up to $1 \frac{1}{2}$ in. in diameter. These were usually subpleural and macroscopically were indistinguishable from caseating tuberculosis.

The heart was normal in size. The muscle was pale, the valves and coronary arteries normal. The thoracic aorta was normal, but slight atheroma was present in the abdominal portion.

The kidneys were enlarged and the capsule stripped easily, leaving minute haemorrhagic spots on the surface. The cortex was widened and pale, with no sharp demarcation from the medulla. The spleen was small and soft with a wrinkled capsule. The liver was enlarged and appeared to be fatty. In the suprarenals there was a loss of cortical pigment and softening of the medulla. The ovaries showed many haemorrhagic cysts.

Histologically, the fibrinoid degenerative lesions of polyarteritis nodosa were found in the kidneys (Fig. 3), spleen, ovaries, suprarenals, and the skin at the site of the rash. The small arteries of the nasal mucosa were similarly affected, and there was also intense infiltration by lymphocytes, plasma cells, and some leucocytes. Multinucleate cells and eosinophils were not present and necrosis had not occurred. Arteritis could not be demonstrated in the myocardium, aorta, liver, pancreas, uterus, or voluntary muscle.

Within the lungs areas of recent intra-alveolar haemorrhage with disruption of the alveolar walls occurred around arteries which showed fibrinoid degeneration of the media. The affected part of the vessel wall was infiltrated by inflammatory cells and periarteritis was often present. This latter type of infiltration was noted only in the lungs (Fig. 4). The pale areas were necrotic, but the histological pattern 


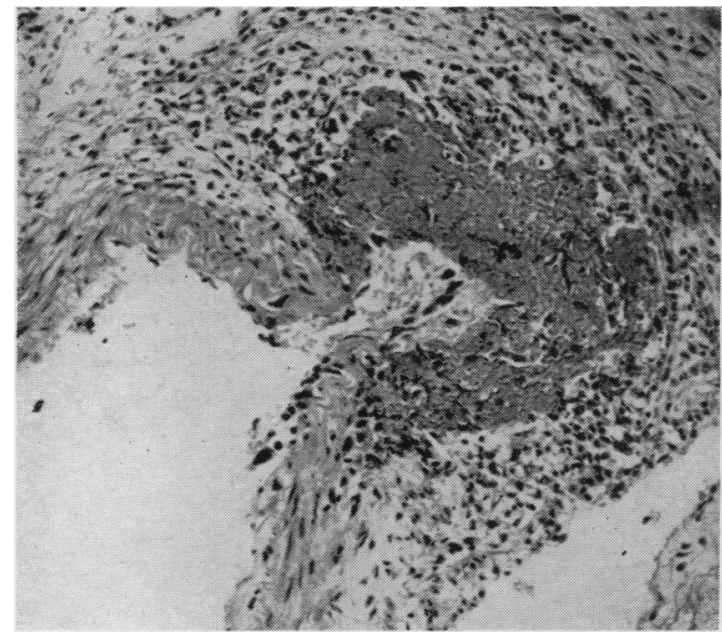

FIG. 3

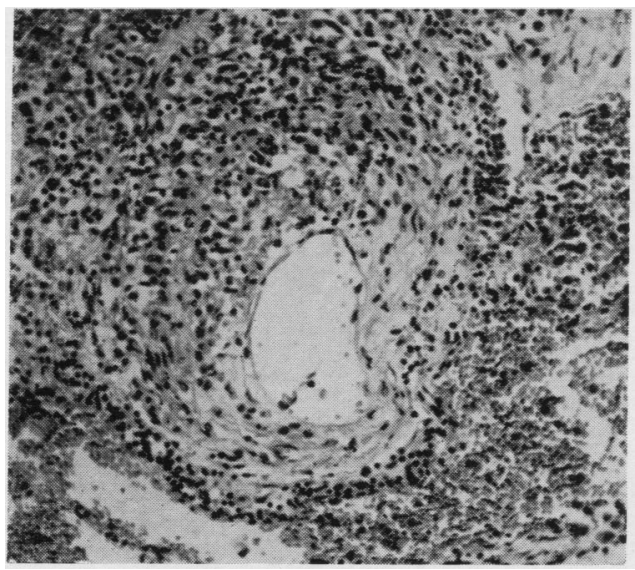

FIG. 4

remained so that thrombosing angiitis was recognizable. At the periphery of the necrosis there was a granulomatous zone with prominent multinucleate giant cells, lymphocytes, and fibroblasts (Fig. 5).

CASE 2.-A 37-year-old housewife was admitted to Farnborough Hospital on December 30, 1953, with a tentative diagnosis of pneumonia with pleural effusion. She was not seriously ill for three months, then more widespread lung lesions developed and she died in respiratory failure on May 29, 1954.

The only illness in the past was a quinsy in 1949. She gave no history of drug sensitivity or allergy. A sister had asthma. There had been no nasal or urinary symptoms at any time.

Her illness lasted six months. It started in November, 1953, with right-sided pleuritic pain, breathlessness on exertion, and mild cough. In December a

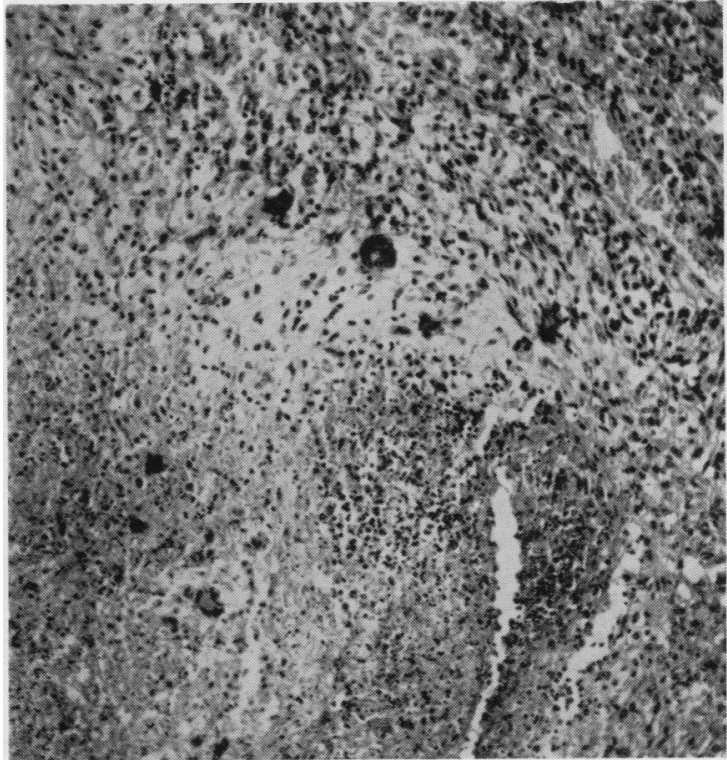

FIG. 5

FIG. 3.-Case 1: medial necrosis of small renal artery. Haematoxylin and eosin, $\times 110$

FIG. 4.-Case 1: polyarteritis of small pulmonary artery with intra-alveolar haemorrhage. Haematoxylin and eosin, $\times 110$.

FIG. 5.-Case 1: giant cell granuloma of lung. Haematoxylin and eosin, $\times 110$.

pleural friction rub was heard, and radiographs showed patchy consolidation above the right diaphragm and a small opacity in the middle zone of the left lung (Fig. 6). On admission to hospital aspiration failed to confirm the presence of pleural fluid; the pain subsided and the radiological shadows on the right side cleared except for some residual pleural reaction. She went home at the end of January.

In March, 1954, pain recurred, this time in the left chest, with a slight cough and some mucoid sputum. Pleural friction and fine rales were heard at the left base. She was readmitted to hospital. Radiographs showed increase in the mottling in the right lower lobe and the same small opacity in the middle zone of the left lung. She became increasingly breathless in April, and radiographs revealed fluffy opacities in the middle and upper zones of both lungs. By the end of May these opacities had spread throughout both lungs (Fig. 7).

Streptomycin and P.A.S. were given for three weeks in March, followed by penicillin and chloramphenicol in April. No antibiotics or sulphonamides were given before or during her first admission. 


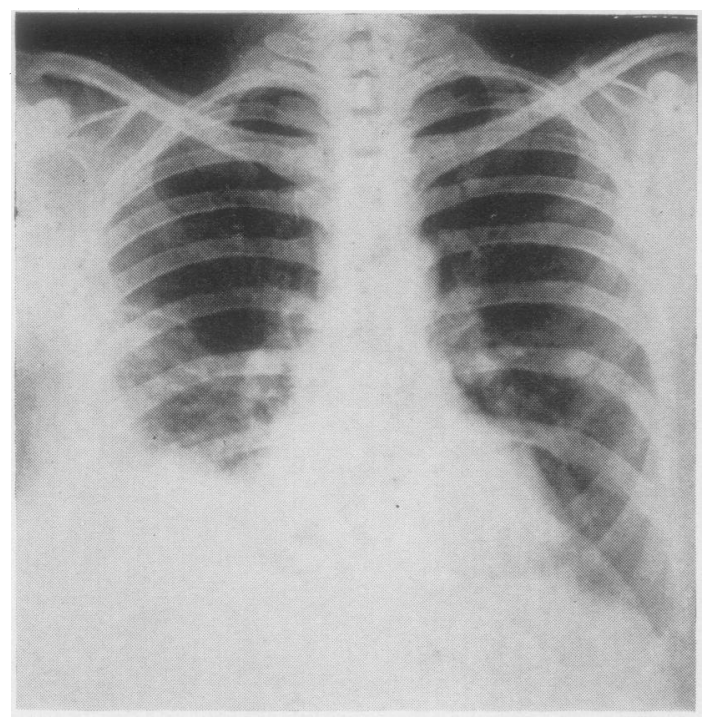

Fig. 6.-Case 2: radiograph of the chest in December, 1953, showing opacity at the right base and some mottling in the middle zone of the left lung.

Her general condition remained fairly good with temperatures under $100^{\circ} \mathrm{F} .\left(37.8^{\circ} \mathrm{C}\right.$.) until May, when she lost weight rapidly. For the two weeks before death there was a high fever. Sputum was never profuse and no nasal discharge was noted. The blood pressure was normal. She became intensely dyspnoeic and cyanosed, and died on May 29, 1954.

Investigations.-Staph. aureus, Strep. viridans, and monilia were grown from sputum on isolated occasions. An intensive search for acid-fast bacilli and fungi failed in 18 specimens. This included three gastric washings and one bronchial swab. Three catheter specimens of urine showed no abnormality. Mantoux skin tests down to $1 / 100$ O.T. were negative. The E.S.R. ranged between 10 and $27 \mathrm{~mm}$. per hour (Westergren). The total and differential leucocyte counts were normal. Brucella and salmonella agglutinin tests were negative and blood culture was sterile. Plasma proteins were $6.3 \mathrm{~g}$. per $100 \mathrm{ml}$.; on electrophoresis a small increase in the gamma globulin fraction was found. An E.C.G. was normal. At bronchoscopy three weeks before death there was no abnormality.

Post-mortem Examination.-Fine adhesions were present over both lungs. The cut surfaces showed numerous red and grey patches, the appearance resembling an extensive bronchopneumonia. The heart muscle was rather brown but otherwise normal. The liver was enlarged and there was a nutmeg pattern. The spleen was enlarged, very soft, and friable. The capsules of both kidneys stripped easily; the cut surfaces showed slight blurring of demarcation of the cortex, otherwise there was no abnormality. No nasopharyngeal lesions were noted.

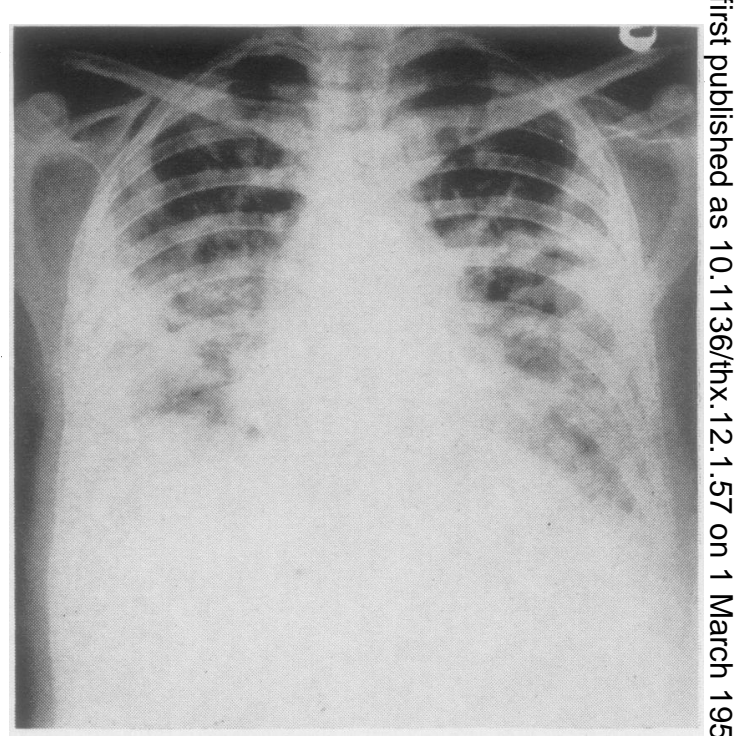

FIG. 7.-Case 2: radiograph of the chest on May 25, 1954, showing dense mottling throughout both lungs.

Microscopically there was fibrinoid degeneration of $\frac{0}{\varnothing}$ the walls of the smaller splenic arteries. The liver $\stackrel{\mathbb{Q}}{2}$ showed severe fatty change and also many small $\vec{B}$ giant-cell granulomata; arterial lesions were not $\frac{0}{3}$ demonstrable.

In the lungs there was widespread affection of the arteries. They showed medial necrosis and infiltration with early intravascular thrombosis (Fig. 8). Intra-alveolar haemorrhage had occurred round such lesions, but this change was not as striking as in $x$ Case 1. Multinucleate giant cells were present in the $\frac{5}{3}$ perivascular tissues and occasionally in the degenerate. vessel wall itself (Fig. 9). Throughout the sections $O$ there were giant cell granulomata, with central necrosis of the larger lesions (Fig. 10). The epithelium 을 of the larger bronchi had desquamated. The mucosa was oedematous with separation of the muscle $\frac{D}{2}$ bundles. Multinucleate giant cells were conspicuous, but there was no accompanying small cell inflam- $\sim$ matory exudation. There was no necrosis or ulceration (Fig. 11).

\section{DEFINITION}

From a study of 35 cases recorded in the litera- $\stackrel{\infty}{?}$ ture there emerges a distinct clinical picture of $\square$ Wegener's syndrome. The disease affects both

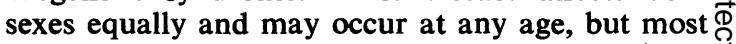
commonly between the ages of 30 and 60 . Some $\overrightarrow{\mathbb{Q}}$ patients give a history of previous sensitivity to penicillin, but evidence of other allergic disorders is usually lacking. 


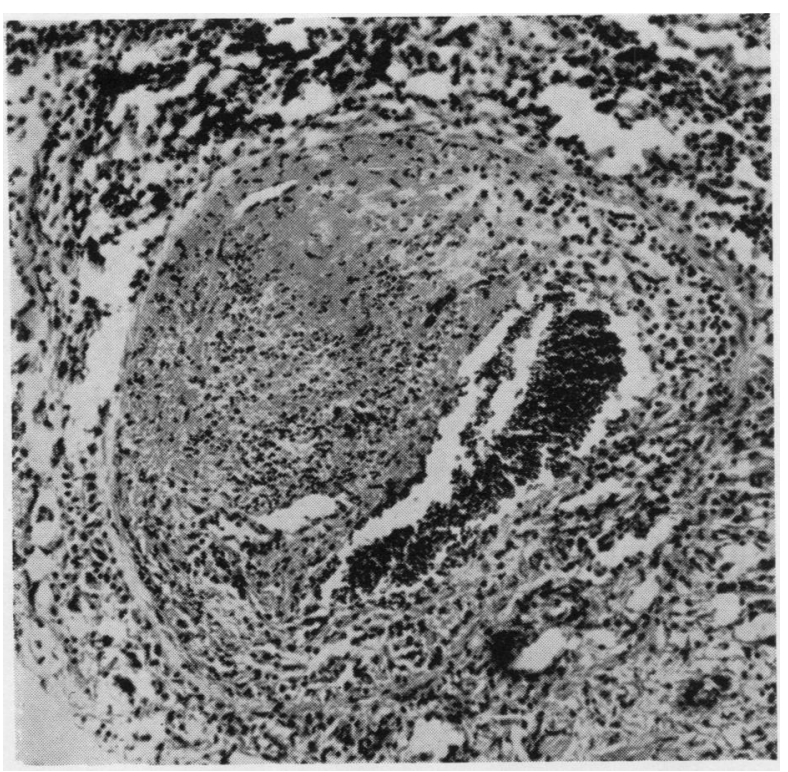

FIG. 8.-Case 2: pulmonary artery showing medial necrosis with thrombosis. Haematoxylin and eosin, $\times 110$.

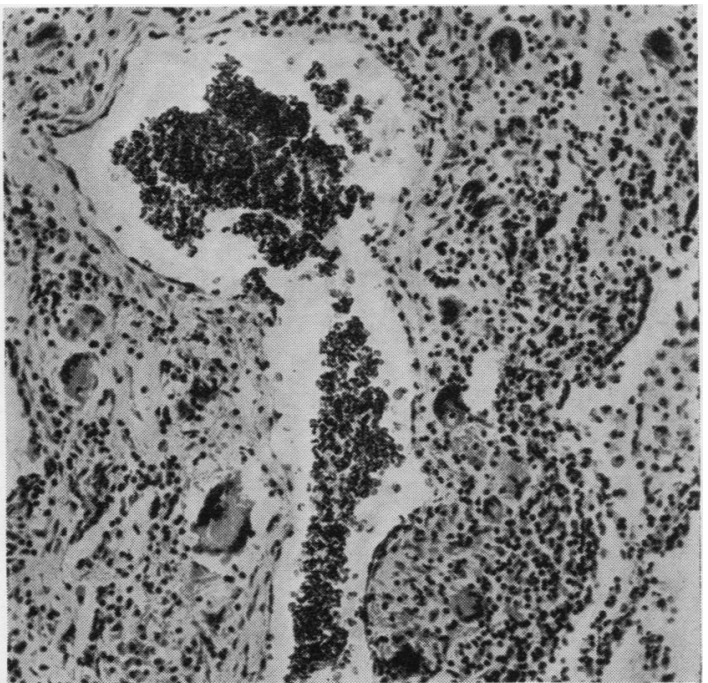

FIG. 9.-Case 2: giant cells in the wall of a degenerate lung vessel. Haematoxylin and eosin, $\times 110$.

The characteristic onset is with intractable rhinitis and sinusitis. The local lesion may go on to destruction of cartilage and bone with involvement of the orbit and consequent conjunctivitis, chemosis, and proptosis. Sometimes it spreads downwards to produce a fistula into the buccal cavity. In a few cases there are no nasopharyngeal lesions.

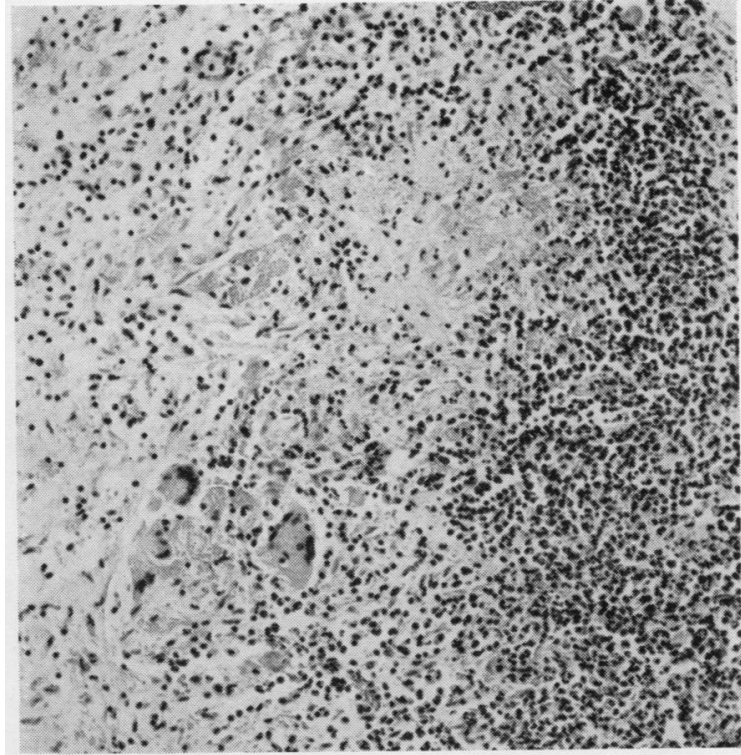

FIG. 10.-Case 2: giant cell granuloma in lung. Haematoxylin and eosin, $\times 110$.

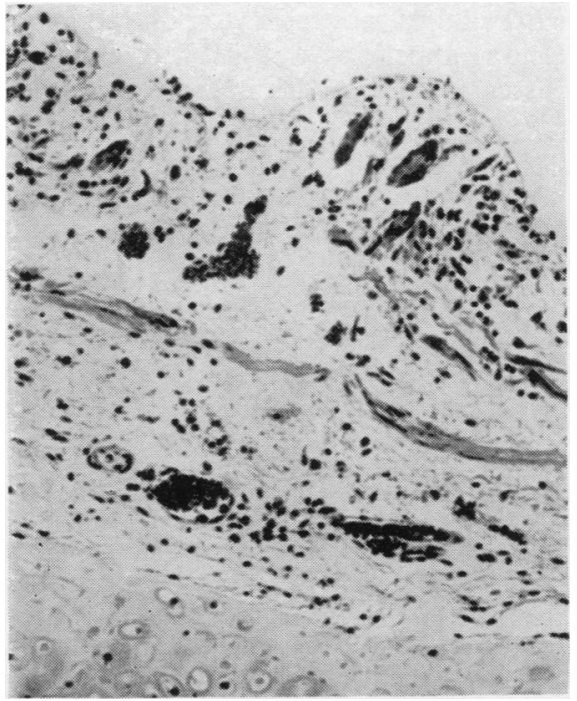

FIG. 11-Case 2: oedematous bronchial mucosa with giant cells. Haematoxylin and eosin, $\times 110$.

The patients complain of cough with a little sputum, sometimes haemoptysis and sometimes of pleural pain. These pulmonary symptoms usually follow the rhinitis and sinusitis, but they may be the presenting features. Dyspnoea becomes prominent in the later stages. The radiological changes vary from small, soft, discrete foci to larger homogeneous infiltrations. 
The patients are usually more ill than the nasopharyngeal and lung manifestations seem to warrant, although the temperature is seldom over $100^{\circ} \mathrm{F}$. The sedimentation rate is raised and there may or may not be a leucocytosis up to 25,000 per c.mm. Eosinophilia is recorded in only two of 19 cases (Fahey and others, 1954).

Superimposed on this basic picture is a variety of symptoms of arthritis, peripheral neuritis, carditis, and skin rashes. These are often transient in character. Finally the illness is dominated by renal failure, which has led to death in all but one of the published cases (Case 7, Fahey and others, 1954). Hypertension is not a feature of this disorder.

Commonly the illness lasts from two to six months; occasional cases linger on for two or more years.

There are two main pathological lesions in this condition. The respiratory tract is involved in a widespread granulomatous process which, except in three published cases (Lindsay, Aggeler, and Lucia, 1944 ; Seidelin and Willcox, 1954 ; Milner, 1955), always affects the lungs, and often the nose, paranasal sinuses, nasopharynx, or epiglottis. The lung lesions appear as well-defined, grey, tumourlike masses or as yellowish necrotic masses. Histologically, they consist of a central necrotic area surrounded by granulation tissue containing neutrophils, lymphocytes, mononuclear, and multinucleated giant cells. Granulomata are scattered in other organs, such as the spleen, liver, and kidneys. No acid-fast bacilli, fungi, or other organisms can be demonstrated in these tissues.

In and around the areas of necrotic lung, active or healed arteritis is to be found. Necrotizing lesions of the arteries and veins are also seen in other organs, particularly in the kidney and spleen, and are less constantly found in the intestines, pancreas, and heart. The kidneys show medial necrosis of the small arteries with fibrinoid degeneration of glomerular loops. In the less acute cases there is crescent formation. Focal granulomata are often seen in the periglomerular region.

\section{Discussion}

Case 1 was typical of Wegener's syndrome as illustrated by the majority of the recorded cases.

Case 2 differed considerably in its clinical aspects, in that the symptoms and signs were confined to the lungs. Necropsy revealed the characteristic combination of giant-cell granulomatosis and arteritis in the lungs. In the liver granulomata were seen but there was no arteritis; in the spleen there was arteritis but there were no granulomata. Unfortunately, the kidneys and nasal mucosa were not preserved for microscopic study. The three negative urinary tests do not certainly exclude renal involvement ; in Weinberg's case (1946), for example, there was no mention of renal disease in life, and yet necropsy revealed typical changes of polyarteritis in the kidneys.

The changes in the lungs in Case 2 at first suggested the diagnosis of tuberculosis, but tubercle bacilli were not found despite an exhaustive search. Minor changes of arteritis were noticed in the lungs, but the first sections of spleen and liver showed nothing unusual. After the experience of Case 1 the blocks were reinvestigated and the full extent of the polyarteritis in lungs and spleen was revealed. This experience is of some importance in the diagnosis of similar obscure cases.

Case 1 had skin changes which have some diagnostic significance for polyarteritis nodosa. There were haemorrhagic herpetiform lesions on an erythematous base. Microscopically the skin showed fibrinoid degeneration of small blood vessels immediately beneath the epithelium. Thesa were surrounded by chronic inflammatory cells. Similar skin changes are described by Ahlström, Liedholm, and Truedsson (1953) and by Walton and Leggat (1956).

Neither patient had blood eosinophilia. A normal eosinophil count is usual in Wegener's granulomatosis in which there is no asthma. This is in contrast to the very high counts seen in those few examples of eosinophilic lung infiltration, with or without asthma, which occasionally develop fatal polyarteritis (Crofton, Livingstone, Oswald, and Roberts, 1952).

The illness in our two cases cannot be attributed directly to a drug. Case 1 had reacted badly to penicillin in 1943, but the rhinitis and sinusitis existed before the exhibition of penicillin and other drugs in 1954. The use of penicillin for the second time may have produced an exacerbation but no more. In our second case there was at no time any suggestion of drug sensitivity. In at least five cases of Wegener's syndrome no sulphonamides or antibiotics had been given (Klinger, 1931 ; Wegener, 1939 ; Stratton, Price, and Skelton, 1953).

\section{Aetiology}

The vascular changes in both our cases were those of polyarteritis nodosa, and the changes in the kidney were also consistent with those found in polyarteritis (Davson, Ball, and Platt, 1948). 
This type of polyarteritis, which has been variously called "the microscopic form of polyarteritis nodosa" or "hypersensitivity angiitis" (Zeek, 1952), differs from the classical variety first described by Kussmaul and Maier (1866). The latter involves chiefly medium-sized arteries, often leads to aneurysm formation, and rarely affects the pulmonary arteries. The only extravascular lesions are infarcts due to interruption of the blood supply. The microscopic form of polyarteritis nodosa affects chiefly small vessels, both arteries and veins, and produces the appearances in the kidneys referred to above.

Our cases resemble the microscopic form of polyarteritis nodosa but differ from it in the presence of necrotizing granulomata, mostly in the respiratory tract. The granulomatous lesions are not infective in origin, as we failed to demonstrate any organisms such as tubercle bacilli or fungi. Similar lesions associated with necrotizing arteritis have been produced in experimental animals by the administration of sulphonamides (Duff, 1946). More, McMillan, and Duff (1946) studied 375 necropsies of patients who had had a considerable amount of sulphonamide therapy. In 22 cases lesions were found which were regarded as directly attributable to this therapy. Granulomata were seen in the heart, liver, and kidneys in 13 cases. In one case microscopic granulomata were found in the lungs and in the bronchial wall. In seven cases there was an acute necrotizing arteritis. Four showed a combination of both features. This strongly suggests that the presence of granulomatosis in a case of polyarteritis nodosa is another aspect of the same disease, and that we are justified in regarding Wegener's syndrome as a subgroup of polyarteritis nodosa.

The presence of granulomata, necrotizing arteritis, and glomerulonephritis together in this syndrome, when any of them individually may be produced in hypersensitivity states, strongly supports the hypothesis that Wegener's syndrome is a disease of hypersensitivity, as presumably is polyarteritis nodosa.

The syndrome differs clinically from common forms of polyarteritis nodosa in the onset, which is always heralded by nasal or pulmonary symptoms. It has been suggested that these initial lesions are due to an infection, and that other organs are sensitized and respond later by widespread arteritis and nephritis (Wegener, 1939). For the reasons set out above, however, we believe that the granulomatous lesions are merely the first manifestations of a hypersensitivity response which later affects the whole arterial system.
The relation of Wegener's granulomatosis to malignant granuloma of the nose is not clear. Most cases of the latter lead to destruction of the surrounding structures and show no evidence of arteritis in the nose or elsewhere. Stratton and others (1953) were able to examine post-mortem material from four typical cases of malignant granuloma of the nose, and found no evidence of polyarteritis anywhere in the body. In other cases (Stratton and others, 1953; Howells and Friedmann, 1950) death followed from polyarteritis. Godman and Churg (1954) describe one case of malignant granuloma in which recent arteritic lesions were found at necropsy.

\section{TREATMENT}

In neither case was there any response to the antibiotics exhibited-that is, penicillin, streptomycin, chloramphenicol, or chlortetracycline. In Case 1 penicillin caused recurrence of a skin reaction which had first occurred in response to penicillin given 12 years before. A similar more severe reaction to streptomycin was shown by Walton and Leggat's case. Adrenocorticotrophic hormone was used only in Case 1 and then at a late stage of the disease when there was advanced uraemia. It is interesting that its administration coincided with an increase in urine volume and a reduction in the blood urea level. It did not prevent the massive outpouring of blood into the alveoli, which was the cause of the patient's death. The only reported case we have found (Fahey and others, 1954, Case 7) of survival from Wegener's syndrome has been treated with A.C.T.H. or cortisone for 19 months. In this case treatment was instituted while the blood urea was still normal, although the urine contained albumin, pus cells, and casts indicating renal damage.

There is a little evidence to suggest that the administration of sulphonamides and antibiotics can bring about an exacerbation of the disease. We think that these drugs should be used with caution in Wegener's syndrome. It would be interesting to learn if cortisone used early, before the onset of renal failure, would at least prolong life in this otherwise fatal disease.

\section{SUMMARY}

Two cases with necrotizing granulomatous lesions of the lungs and generalized polyarteritis are described. One had nasal lesions and died in renal failure; the other had extensive pulmonary infiltration, but no gross nasal or renal lesions, and died in respiratory failure. 
Both are examples of Wegener's syndrome, and the clinical and pathological features of this condition are discussed.

The relationship of Wegener's granulomatosis to polyarteritis nodosa and to malignant granuloma of the nose is briefly discussed.

Case 1 was referred to us by Dr. H. D. Cullimore, of Staines. We are indebted to Dr. D. N. Dobbie, of Farnborough Hospital, for allowing us to study Case 2, and to Dr. M. King for the necropsy report.

\section{REFERENCES}

Ahlström, C. G., Liedholm, K., and Truedsson, E. (1953). Acta med. scand., 144, 323.

Crofton, J. W., Livingstone, J. L., Oswald, N. C., and Roberts, A. T. M. (1952). Thorax, 7, 1 .

Davson, J., Ball, J., and Platt, R. (1948). Quart. J. Med., 17, 175.
Duff, G. L. (1946). Amer. J. Path., 22, 646.

Fahey, J. L., Leonard, E., Churg, J., and Godman, G. (1954). Amer. J. Med., 17, 168.

Godman, G. C., and Churg, J. (1954). A.M.A. Arch. Path., 58, 533.

Howells, G. H., and Friedmann, I. (1950). J. clin. Path., 3, 220.

Klinger, H. (1931). Frankfurt. Z. Path., 42, 455.

Kussmaul, A., and Maier, R. (1866). Dtsch. Arch. klin. Med., 1, 484. Lindsay, S., Aggeler, P. M., and Lucia, S. P. (1944). Amer. J. Path., $20,1057$.

McCallum, A. G. (1954). J. Laryng., 68, 560.

Milner, P. F. (1955). Brit. med. J., 2, 1597.

More, R. H., McMillan, G. C., and Duff, G. L. (1946). Amer. J. Path., 22, 703.

Seidelin, P., and Willcox, A. (1954). Arch. Middx Hosp., 4, 171.

Stratton, H. J. M., Price, T. M. L., and Skelton, M. O. (1953). Brit. med. J., $1,127$.

Walton, E. W., and Leggat, P. O. (1956). J. clin. Path., 9, 31.

Wegener, F. (1936). Verh. dtsch. path. Ges., 29, 202.

(1939). Beitr. path. Anat., 102, 36.

Weinberg, T. (1946). Amer. J. clin. Path. 16, 784.

Zeek, P. M. (1952). Ibid., 22, 777. 